\title{
European Economic Integration and the Effectiveness of Employment Policies
}

\author{
K.C. Fung \\ University of California, Santa Cruz \\ Chelsea C. Lin \\ National Dong Hwa University \\ Andrea M. Maechler \\ International Monetary Fund
}

\begin{abstract}
This paper examines the qualitative impact and the degree of effectiveness of several labor market policies when domestic union's wage response and economic integration are explicitly taken into account. The employment policies considered include payroll tax cuts, unemployment benefits cuts, aggregate demand expansion and wage subsidies. It is shown that with endogenous wages and an open economy, these policies can in some cases become more potent. But in other instances, they become less effective. In fact, under some conditions derived in this paper, employment policies can even be counterproductive, leading to a drop in domestic employment.

- JEL Classifications: F15, F42, L51

- Key words: European unemployment, Economic integration, Labor market structure

\footnotetext{
*Corresponding address: K.C. Fung, Department of Economics, University of California, Santa Cruz, CA 95064, USA, Tel: +1-831-459-3273, Fax: +1-831-459-5900, E-mail: kcfung@cats.ucsc.edu. K.C. Fung is also a Visiting Scholar at Stanford University and a Senior Research Fellow at the University of Hong Kong.

@2005-Center for International Economics, Sejong Institution, All Rights Reserved.
} 


\section{Introduction}

Unemployment has been a core issue in the making of the European Union (EU). ${ }^{1}$ From 1993 to 1997, the fifteen members of the EU had unemployment rates that exceeded consistently 10 per cent. The 1997 European summit held in Luxembourg dealt primarily with questions regarding job creation and labor absorption in the EU. Despite modest improvement in recent years, European unemployment remains stubbornly high. In 2001, at 7.4 percent, the overall unemployment rate in the EU is still at a very high level compared to that in the US, where unemployment is below 5 per cent. Table 1 below presents EU unemployment rates from 1985 to 2001.

In view of the enlargement of the $\mathrm{EU}$, the role of the $\mathrm{EU}$ in its ability to promote a higher level of employment and social protection has become an increasingly important issue on the political and economic agenda of the EU.2 In 1993, the European Council provided a powerful catalyst by placing the theme of employment on the EU agenda. In

Table 1. Unemployment Rates in European Union

\begin{tabular}{lcccccccccccccccccc}
\hline & 1985 & 1986 & 1987 & 1988 & 1989 & 1990 & 1991 & 1992 & 1993 & 1994 & 1995 & 1996 & 1997 & 1998 & 1999 & 2000 & 2001 \\
\hline Austria & 3.7 & 4.0 & 4.3 & 4.1 & 3.8 & 4.1 & 4.5 & 4.7 & 5.4 & 5.3 & 5.3 & 5.6 & 5.7 & 5.7 & 5.3 & 4.7 & 4.9 \\
Belgium & 10.1 & 10.01 & 9.8 & 8.8 & 7.4 & 6.6 & 6.4 & 7.1 & 8.6 & 9.8 & 9.7 & 9.5 & 9.2 & 9.3 & 8.6 & 6.9 & 6.6 \\
Denmark & 6.6 & 5.0 & 5.0 & 5.7 & 6.8 & 7.2 & 7.9 & 8.6 & 9.6 & 7.7 & 6.8 & 6.3 & 5.3 & 4.9 & 4.8 & 4.4 & 4.3 \\
Finland & 5.1 & 5.4 & 5.1 & 4.6 & 3.1 & 3.2 & 6.6 & 11.7 & 16.4 & 16.6 & 15.4 & 14.6 & 12.7 & 11.4 & 10.3 & 9.8 & 9.1 \\
France & 10.2 & 10.4 & 10.5 & 10.0 & 9.3 & 8.9 & 9.4 & 10.4 & 11.7 & 12.0 & 11.4 & 12.1 & 12.2 & 11.5 & 10.8 & 9.4 & 8.7 \\
Germany & 8.0 & 7.7 & 7.6 & 7.6 & 6.9 & 6.2 & 5.4 & 6.4 & 7.6 & 8.1 & 7.9 & 8.5 & 9.4 & 8.9 & 8.2 & 7.5 & 7.4 \\
Greece & 7.8 & 7.4 & 7.4 & 7.7 & 7.5 & 7.0 & 7.7 & 8.7 & 9.7 & 9.6 & 9.1 & 9.8 & 9.8 & 11.1 & 12.0 & 11.2 & 10.4 \\
Ireland & 16.5 & 17.0 & 16.7 & 16.2 & 14.9 & 12.8 & 14.4 & 15.1 & 15.7 & 14.7 & 12.2 & 11.7 & 10.4 & 7.6 & 5.6 & 4.3 & 3.9 \\
Italy & 8.6 & 9.9 & 10.2 & 10.5 & 10.2 & 9.1 & 8.6 & 8.8 & 10.2 & 11.2 & 11.7 & 11.7 & 11.8 & 11.9 & 11.5 & 10.7 & 9.6 \\
Luxembourg & 1.7 & 1.5 & 1.7 & 1.6 & 1.4 & 1.3 & 1.4 & 1.6 & 2.1 & 2.7 & 3.0 & 3.3 & 3.6 & 3.1 & 2.9 & 2.6 & 2.6 \\
Netherlands & 9.2 & 8.4 & 8.0 & 7.7 & 6.9 & 6.0 & 5.4 & 5.4 & 6.6 & 7.6 & 7.1 & 6.6 & 5.5 & 4.2 & 3.2 & 2.6 & 2.2 \\
Portugal & 8.8 & 8.8 & 7.3 & 6.0 & 5.2 & 4.9 & 4.3 & 4.1 & 5.5 & 6.9 & 7.2 & 7.3 & 6.8 & 5.0 & 4.4 & 4.0 & 4.1 \\
Spain & 17.8 & 17.4 & 16.7 & 15.9 & 14.2 & 13.3 & 13.4 & 15.1 & 18.9 & 20.2 & 19.1 & 18.5 & 17.2 & 15.4 & 12.9 & 11.4 & 10.5 \\
Swden & 2.8 & 2.5 & 2.1 & 1.7 & 1.5 & 1.7 & 3.0 & 5.3 & 8.2 & 8.0 & 7.7 & 8.0 & 8.0 & 6.5 & 5.6 & 4.7 & 4.0 \\
UK & 11.6 & 11.8 & 10.2 & 7.8 & 6.1 & 5.9 & 8.2 & 10.2 & 10.3 & 9.4 & 8.5 & 7.9 & 6.5 & 5.9 & 6.0 & 5.5 & 5.1 \\
EU & 9.9 & 9.9 & 9.6 & 8.9 & 8.1 & 7.5 & 7.7 & 8.8 & 10.2 & 10.6 & 10.1 & 10.3 & 10.0 & 9.4 & 8.7 & 7.8 & 7.4 \\
OECD & 7.4 & 7.4 & 7.0 & 6.3 & 5.8 & 5.7 & 6.3 & 7.0 & 7.7 & 7.6 & 7.3 & 7.2 & 6.9 & 6.7 & 6.6 & 6.1 & 6.4 \\
\hline
\end{tabular}

Source: OECD Economic Outlook No. 72-Statistical Annex Tables, 2002.

\footnotetext{
'The average rate of Western European unemployment remains at above 9 per cent.

${ }^{2}$ On October 9, 2002, European Commission President Romano Prodi announced that ten of the candidate countries, Cyprus, the Czech Republic, Estonia, Hungary, Latvia, Lithuania, Malta, Poland, the Slovak Republic and Slovenia, are on track to complete negotiations by the end of this year and will join the EU as full members by 2004 .
} 
1997, the Amsterdam Treaty included a separate chapter dealing explicitly with employment. Shortly thereafter, at the 1997 European summit held in Luxembourg, the European Council decided to issue guidelines and recommendations for the Member States to help them raise employment. More recently, during the European summit in March 2000, the European Council decided that it should have a higher degree of involvement in coordinating the various measures of the Council pertaining to the promotion of growth and employment.

Over the years, there have been several important diagnoses for the persistent European unemployment ills. These include excessively high real wages (Bruno and Sachs, 1985), hysteresis in the labor market (Blanchard and Summer, 1986), rigidities due to the extensive welfare state (Giersch, 1985; Lindbeck, 1985), externalities created by the union insiders (Lindbeck and Snower, 1986) and insufficient aggregate demand (Coen and Hickman, 1987). ${ }^{3}$ More recently, Nickell (1997) provided an important survey of how labor market rigidities in Europe can lead to higher unemployment rates compared to those in the United States.

Siebert (1997) argued that institutional changes affecting Europe's labor markets are a central reason for Europe's poor labor market performance. Blanchard and Wolfer (2000) provided evidence that labor market policies and institutions matter significantly in explaining the rise of European unemployment.

Despite the divergent views regarding the origins of EU's poor employment record, there seems to be a gradual consensus that both demand-side and supplyside policies are necessary ingredients for raising employment (see, for example, Blanchard et al., (1986); Nickell and Layard, 1998). ${ }^{4}$ Many studies have investigated the impact of labor market institutions on EU's unemployment. However, the exiting literature still lacks a model to explicitly link the EU integration, unions and the social security systems. This paper examines the impact and the degree of effectiveness of employment-promoting policies when wages are endogenously determined by labor unions and when the international product markers are increasingly integrated.

In addition, even though the ability of labor unions to set high wages is frequently cited as an important cause of the labor market rigidity, few studies have focused explicitly on how wage determination by the unions can affect the

\footnotetext{
${ }^{3}$ The explanations are interrelated and are not necessarily mutually exclusive.

${ }^{4}$ Fung (1989) examines the use of profit-sharing as a tool to lower the high unemployment rate in Europe.
} 
effectiveness of various proposed solutions. ${ }^{5}$ Most economists agree that generally economic integration is beneficial to Europe as a whole. But few have addressed the potential loss of some degree of national autonomy in pursuing domestic employment goals. ${ }^{6}$

In this paper we highlight explicitly how economic integration and endogenous wage setting by unions will affect the efficacy of various policies aimed at expanding employment. These demand and supply-side policies are drawn from suggestions that have been frequently proposed as promising remedies for the European unemployment problem. ${ }^{7}$ On the supply side, we consider payroll tax cuts and wage subsidies as policies that reduce the costs of labor. We also examine cuts in unemployment benefits, which are proposed to reduce the excesses of the welfare state. Lastly, on the demand side, we analyze the policy of an increase in government expenditure.

By taking the unions' responses and economic integration explicitly into account, it is shown in this paper that wage endogeneity and the openness of the economy can in some instance magnify the effectiveness of the employment policies.

But in other instances, their efficacy is dampened. In fact, under some conditions, these policies can even be counterproductive, i.e., employment can decline instead of increase with traditional employment-promoting policies.

The rest of the paper is organized as follows: in the next section, we provide a general framework for our analysis, focusing on how integration and wage-setting unions can significantly affect the results. In Section 3, we briefly present the conventional results of the policies analyzed in isolation. In Sections 4 and 5, we reexamine the effectiveness of these policies in the presence of responses from unions and when the economy is open, using standard specific models. Some concluding remarks are provided in the last section.

\footnotetext{
${ }^{5}$ There are some exceptions, see for example Lindbeck and Snower (1989).

${ }^{6}$ Some related papers on this issue include Alogoskoufis (1990), Fung and Huizinga (1989), Abowd and Lermieux (1990), and Minford (1983).

${ }^{7}$ These proposed remedies can be found in e.g., Blanchard et al. (1986), Layard and Calmfors (1987), and Lawrence and Shultze (1987).
} 


\section{General Framework}

We highlight here in a general framework the importance of integration and wage setting on the efficacy of employment policies. In the literature, the conventional analysis can be described as follows. The union or the firm is considered in isolation. The parameters for the initial economic environment are given as $\Omega$

The union or the firm incorporates the effects of $\Omega$ when choosing its optimal strategies (wage $w$ for the union or output $x$ for the firm). The payoff is either returns to the firm $\pi$ or returns to the union $V$. Either $\pi$ or $V$ implicitly defines the employment level $l(\Omega)$.

Now consider a change of $\Omega$ to $\Omega$ (e.g., a cut in payroll tax). The firm or the union chooses a different optimal strategy, leading to a new employment level $\dot{l}(\Omega)$. It is generally shown that the change to employment $(\dot{l}-l)=\Delta l$ is positive.

As presented above, the argument is eminently reasonable. However, it neglects the possible impact of how a change in $\Omega$ affects the interactions between first, the domestic firm and the domestic union, and secondly, in an open economy, the interactions between the domestic firm-unions and the competitive foreign firmunions.

Taking these interactions into account explicitly, the game is described as follows. The initial environment is still given by $\Omega$. The $n$ unions, some of which can be foreign, move first. The $n$ firms, including some foreign producers, move second. All agents take $\Omega$ into account when choosing their best strategies. The unions take the behavior of the firms in the second stage into account when choosing their vector of strategies $\bar{\omega}$ independently. The firms then choose their vector of strategies $\bar{x}$. The equilibrium is subgame perfect. The payoffs to the union $i$ and firm $i$ are $V_{i}(\bar{w}, l,(\bar{w}), \Omega)$ and $\pi_{i}\left(\bar{x}(\bar{w}), l_{i}(\bar{w}), \Omega\right)$. Employment to firm $i$ is $l_{i}(\bar{w}(\Omega), \Omega)$.

Note that employment to firm $i$ depends on the policies $\Omega$ directly as well as the whole vector of independently chosen wage $\bar{w} .{ }^{8}$ With a change of the policies to $\bar{\Omega}$, then employment is $l_{i}(\bar{w}(\Omega), \Omega)$. Assume then $m$ unions and $m$ firms $m \leq n$ belong to the domestic country. Then the domestic employment under the

\footnotetext{
${ }^{8}$ For ease of notation, we have suppressed outputs as separate arguments in the labor demand function. Note also that the optimal outputs in turn depend on wages.
} 
alternative policy environments $\Omega$ and $\Omega$ are $\bar{L}(\Omega)=\sum^{n} l_{i}\left(w_{1}(\bar{\Omega}), \ldots w_{i}(\bar{\Omega})\right.$, $\left.\ldots w_{m}(\Omega), \ldots w_{n}(\Omega), \Omega\right)$ where $w_{1}$ to $w_{m}$ are domestic wages affected by the policy parameters and $w_{m+1}$ to $w_{n}$ are foreign wages similarly affected by the domestic economic environments.

For ease of comparison, we can focus on symmetric games so that $L_{i}(\Omega)=\frac{1}{n} L(\Omega)$ and $\bar{L}_{i}(\bar{\Omega})=\frac{1}{n} L(\bar{\Omega})$. The change in employment to each firm is $\bar{L}_{i}(\Omega)-L_{i}(\Omega)=\Delta L_{i}$.

In general, due to induced wage responses from firstly, domestic unions and secondly, foreign unions, $\Delta L_{i}$ is typically not the same as $\Delta l$ considered in the conventional analysis, even given identical demand and cost conditions. In other words $\Delta L_{i} \gtrless \Delta l$. In fact, with sufficient wage responses, $\Delta L_{i}$ can be negative even though $\Delta l$ is typically positive, as stressed in the literature. Basically the above presentation shows that generally wage responses of the domestic union matters. Furthermore, whether the economy is open or closed also matters. In an open economy, foreign firms react to a domestic change of $\Omega$, which induces further wage responses from foreign unions. These wage linkages can magnify or dampen the efficacy of domestic employment policies. In some instances, employment can even drop.

It is not the point here to dispute the potentially important beneficial effects of these policies. Rather the paper highlights some interesting, neglected properties of wage endogeneity and economic integration. Given these properties, some caution should perhaps be drawn in implementing the policies studied.

In the next section, we consider specific models to more concretely illustrate our points. These models are standard approaches widely used in the literature. ${ }^{9}$

Conditions are derived to show situations where the effectiveness of these policies are reduced or enhanced. Conditions are also derived under which employment policies can be counterproductive. The models are illustrative but given theabove discussions, the basic message of the paper should remain in more complex settings.

\section{Employment Policies in Isolation}

We briefly examine the impact of several employment policies when the responses from the unions and/or from foreign firms are not considered. We treat in

\footnotetext{
${ }^{9}$ These approaches can be found in for example Bean, Layard and Nickell (1986).
} 
turn the policies that affect firms directly and those that affect unions directly. Payroll taxes $\tau$, wage subsidies $s$ and aggregate demand expenditure $A$ all affect the firm's profit function $\pi$ directly:

$$
\pi=P(x, A) x-w(1+\tau) l+s l-F
$$

$P$ is the product price, $x$ is the firm's output, and $F$ is fixed costs. Profit maximization yields:

$$
\begin{gathered}
\pi_{x}=P+x P_{x}-w(1+\tau) l_{x}+s l_{x}=0 \\
\pi_{x x}<0
\end{gathered}
$$

Differentiating (2) and using the derived labor demand, it is straightforward to establish the conventional results: ${ }^{10}$

$$
\begin{aligned}
& \partial l / \partial s>0 \\
& \partial l / \partial \tau<0 \\
& \partial l / \partial A>0
\end{aligned}
$$

For cuts in unemployment benefits $b$, they affect the union behavior directly. For simplicity we assume that the union maximizes its rents $V=(w-b) l$. All the qualitative results, however, remain robust if we change the union to a utilitarian one similar to that in Oswald (1982) or McDonald and Solow (1981). Furthermore, the results of the paper will be unchanged if we allow the unions and the firms to negotiate over the wage. ${ }^{11}$ Maximization of the union objective implies:

$$
\begin{gathered}
V_{w}=l+(w-b) l_{w}=0 \\
V_{w w}<0
\end{gathered}
$$

From (4) and the labor demand function we obtain

\footnotetext{
${ }^{10}$ For the case of an increase in aggregate expenditure, we assume that $\pi_{x A}>0$ to obtain $\partial l / \partial A>0$. $\pi_{x A}>0$ implies that an increase in aggregate demand will raise marginal profits.

${ }^{11}$ There is of course much controversy over whether the firms are on their labor demand curves. But it seems that it is a fairly standard practice for employment to be left for the firm to determine, see Farber (1986). There also seems to be some evidence that firms are indeed on the labor demand schedules (Oswald, 1984).
} 


$$
\partial l / \partial b<0
$$

Expression (3) and (5) are standard results when discussing the possible impact of employment policies. They show that cuts in payroll taxes and unemployment benefits and increases in wage subsidies and government expenditures will raise employment. They are derived, however, without paying explicit attention to optimal responses derived from the domestic firms-union nexus and, in the case of an open economy, from the double domestic and foreign firms-union nexus.

\section{Employment Policies in Closed Economy with a Domestic Union}

In this section we incorporate explicitly the domestic wage responses to the employment policies. Since cuts in unemployment benefits a.ect the unions directly, the union's wage response is already captured in the standard treatment. The impact in this instance is given by (4) and (5). We next turn to an analysis of cuts in payroll taxes, wage subsidies and increased government expenditure.

Using (2) and (4), we derive the labor demand function: $l(x(\tau, s, A), w(\tau, s, A))$.

The derived demand for labor depends on output and the union wage setting, both in turn are affected by our policies. The second effect is the domestic union wage effect, which we will highlight. First consider a cut in payroll taxes. By (4), we have:

$$
\frac{\partial w}{\partial \tau}=-\Phi\left(\hat{w}-\hat{\varepsilon}_{\tau}\right)
$$

where $\Phi \equiv \frac{l_{\tau}}{V_{w w w} \hat{w}}>0, \hat{w} \equiv\left(\frac{w}{w-b}\right)$, and $\hat{\varepsilon_{\tau}} \equiv-\left(\frac{\partial l_{\tau}}{\partial w} \frac{w}{l_{\tau}}\right)$ is the elasticity of firms employment response to a cut in payroll taxes, $l_{\tau}$, with respect a change in wages, $w$. If $\hat{\varepsilon_{\tau}}$ is positive, $\hat{\varepsilon_{\tau}}$ shows how a rise in wages may decrease firms' response to lower payroll taxes. If $\hat{\varepsilon_{\tau}}$ is elastic, at higher wages, firms respond much less to a cut in $\tau$ than they would at lower wages. According to equation (6), if $\hat{w}-\hat{\varepsilon_{\tau}}$ is positive (negative), the unions respond to a cut in payroll taxes by raising (reducing) their wage demands. To better explain the intuition of this result, let us assume for now that there exist no unemployment benefits, i.e., $\mathrm{b}=0$. In this case, $\hat{w}=1$ and $\frac{\partial w}{\partial \tau}>0$ when $\hat{\varepsilon_{\tau}}>1$. In response to lower payroll taxes, unions are willing to lower their wage demands if, at these lower wages, firms' (positive) employment response to a cut in payroll taxes rises more than proportionately to the rise in wages. In other words, unions are willing to reduce their wage demands if, at lower wages, 
firms respond more than proportionately to a cut in $\tau$ by raising employment. In the presence of unemployment benefits, i.e., when $b>0$, unions tend to care less about employment and more about wages. Thus, unions are willing to accept lower wages only if, at these lower wages, the employment effect of a cut in payroll taxes more than compensates for the lower wages, or when $\hat{\varepsilon_{\tau}}>\hat{w}>1$.

The total effect of a change of the payroll tax on employment is

$$
\frac{d l}{d \tau}=l_{\tau}+\left(\frac{\partial w}{\partial \tau}\right) l_{w}=\hat{I}_{\tau}+\hat{U}_{\tau}<0
$$

where $\hat{I}_{\tau}$ refers to the direct effect of a change in payroll taxes on employment. We will refer to this effect as to the "direct firm employment effect." $\hat{I}_{\tau}$ expresses how a firm, in the absence of unions, would adjust its labor demand in response to a change in the payroll taxes, $\tau$. From equation (6) in Section 3, we know that $\hat{I}_{\tau}$ is necessarily negative. In response to a fall in payroll taxes, firms direct response is to raise employment. But the sign of $\hat{U}_{\tau}$ is ambiguous. $\hat{U}_{\tau}$ examines how unions, by adjusting their wage demands, affect the equilibrium employment level. In the absence of unions, $\hat{U}_{\tau}$ is zero and a cut in payroll taxes has a positive effect on employment. In the presence of unions, $\hat{U}_{\tau}$ may be either positive or negative, depending on whether unions raise or reduce their wage demands in response to lower payroll taxes. We will refer to this effect as the "union wage effect."

Assuming lower payroll taxes induce unions to reduce their wage demand $\left(\frac{\partial w}{\partial \tau}<0\right)$, a cut in payroll taxes will result in a higher demand for labor. But if unions react to lower payroll taxes by raising their wage demands, the aggregate effect of a cut in payroll taxes on employment can be either positive or negative, depending on the relative strength of the direct firm employment effect and the union wage effect.

Substituting (6) into (7), we find immediately our first result: If $\left(\hat{w}-\hat{\varepsilon_{\tau}}\right)>0$, the presence of the union dampens the effectiveness of a payroll tax cut on; if, however, $\hat{w}-\hat{\varepsilon_{\tau}}<0$, the union will magnify the impact of a payroll tax cut on employment.

$$
\frac{d l}{d \tau}=l_{\tau}-\Phi\left(\hat{w}-\hat{\varepsilon_{\tau}}\right) l_{w}<0
$$

Let's take the standard case where a cut in payroll taxes raises employment.

According to equation (8), this result is true when $\left(\hat{w}-\hat{\varepsilon}_{\tau}\right)<0$. We have shown above in equation (6) that in the absence of unemployment benefits (when $b=0$ ) 
$\left(\hat{w}-\hat{\varepsilon}_{\tau}\right)<0$ if $\varepsilon_{\tau}>1$, in which case $\frac{\partial w}{\partial \tau}<0$. A cut in payroll taxes induces firms to raise their demand for labor. In addition, assuming that firms' response to lower taxes is greater in a low wage environment, unions are willing to reduce their wage demands, which further raises employment.

Let us now consider the case where a cut in payroll taxes reduces employment.

We know from equation (7) that this outcome can only occur when unions respond to a reduction in payroll taxes by raising their wage demands (when $\frac{\partial w}{\partial \tau}$ is negative). We also know from equation (8) that the aggregate employment effect of a reduction in payroll taxes is greater when: (i) firms' direct response to a cut in payroll taxes, $l_{\tau}$, is small; (ii) firms' labor demand is highly sensitive to higher wages ( $l_{w}$ is relatively large); and (iii) when firms' responsiveness to a cut in payroll taxes is relatively inelastic with respect to wages $\left(\hat{\varepsilon}_{\tau}\right.$ is small). Finally, we know from equation (6) that in the absence of unemployment benefits $(b=0)$, unions respond to lower payroll taxes by raising their wage demands when $\hat{\varepsilon}_{\tau}<1$.

In the presence of unemployment benefits $(b>0)$, unions are willing to raise their wage demands even when these higher wages are dampening the positive employment effect of reducing payroll taxes, or when $\hat{\varepsilon}_{\tau}>\hat{w}>1$. This means that in the presence of unions, the presence of unemployment benefits, which raises the range of parameters under which unions respond to lower payroll taxes by requesting higher wages, reduces the effectiveness of an employment policy.

We can further simplify equation (8):

$$
\frac{d l}{d \tau}=\Theta\left(\hat{w}-\hat{\varepsilon_{\tau}}+\hat{\gamma}\right)>0
$$

where $\Theta=\frac{l_{w} l_{\tau}}{V_{w w} \hat{w}}=l_{w} \Phi<0$ and $\hat{\gamma}=\left(-\frac{\partial l_{w}}{\partial w} \frac{w}{l_{w}}\right)$ is the wage elasticity of the slope of the labor demand curve. From (9), we immediately obtain our second result:

If $\left(\hat{w}-\hat{\varepsilon_{\tau}}+\hat{\gamma}\right)>0$, employment rises with a cut in the payroll taxes; in contrast, if $\left(\hat{w}-\hat{\varepsilon}_{\tau}+\hat{\gamma}\right)<0$, employment actually falls. This result illustrates that with the union's wage response taken into account, we can obtain the "perverse" result that cutting payroll taxes can lead to a decline in employment.

For simplicity, let's assume again that workers do not enjoy unemployment benefits. In this case, equation (9) says that a cut in payroll taxes can lead to a perverse effect on employment if $\hat{\gamma}+\hat{\varepsilon_{\tau}}>1$. A cut in payroll taxes has two effects: first, it raises employment directly (through $l_{\tau}$, the direct firm employment effect); second, it may induce unions to raise their wage demands, which in turn has a 
negative effect on employment. The aggregate effect on employment will depend on firms' responsiveness to, respectively, a lower payroll taxes and higher wages.

According to our results, a cut in payroll taxes may actually reduce aggregate employment if, in response to a cut in payroll taxes, unions demand higher wages and firms' (negative) employment response to these higher wages is stronger than their (positive) response to lower payroll taxes. In other words, a cut in payroll taxes reduces employment if the employment gain induced by lower payroll taxes is weaker than the employment loss induced by higher wages.

To highlight this point, let's assume that the shift of the labor demand due to a change in payroll tax is isoelastic (i.e., $\hat{\varepsilon_{\tau}}=0$ ). Then (9) is reduced to:

$$
\frac{d l}{d \tau}=\frac{l_{w} l_{\tau}}{V_{w w}}(1-R)=\hat{w} \Theta(1-R)
$$

where $R=-(w-b) \frac{l_{w w}}{l_{w}}$ is a measure of the relative convexity of the labor demand.

Since $\Theta$ is negative by construction, in the absence of unemployment benefits, a cut in payroll taxes yields a perverse effect on employment if $R>1$. Intuitively, lower payroll taxes reduce aggregate employment if a one percent increase in wages increases firms' (negative) employment response to higher wages by more than one percent. In other words, if firms' employment response to higher wages is highly convex, a cut in payroll taxes that induces unions to raise their wage demand can have a perverse effect on employment. This result is more likely to occur in the presence of unemployment benefits. When $b>0$, unions are more interested in high wages than in high employment. As a consequence, they are willing to raise their wage demands even when these higher wages are dampening the positive employment effect of lower payroll taxes.

This result is not specific to payroll taxes but may apply to other employment policies, such as an increase in wage subsidies and an increase in aggregate demand. The analysis and the results are the same as in the case of the payroll tax cuts. The total effects on employment are

$$
\frac{d l}{d s}=l_{s}+\left(\frac{\partial w}{\partial s} \frac{\partial l}{\partial w}\right)=\hat{I}_{s}+\hat{U}_{s}
$$

and

$$
\frac{d l}{d A}=l_{A}+\left(\frac{\partial w}{\partial A} \frac{\partial l}{\partial w}\right)=\hat{I}_{A}+\hat{U}_{A}
$$


Using the analogue of (6) we obtain the change to the union's wage as the policies change:

$$
\begin{aligned}
& \frac{\partial w}{\partial s}=\frac{-l_{s}\left(\hat{w}-\hat{\varepsilon_{s}}\right)}{V_{w w} \hat{w}} \\
& \frac{\partial w}{\partial A}=\frac{-l_{s}\left(\hat{w}-\hat{\varepsilon_{A}}\right)}{V_{w w} \hat{w}}
\end{aligned}
$$

$\hat{\varepsilon}_{s}$ and $\hat{\varepsilon_{A}}$ are defined similarly as in the payroll tax case as $\hat{\varepsilon_{s}}=-\left(\frac{\partial l_{s}}{\partial w} \frac{w}{l_{s}}\right)$ and $\hat{\varepsilon_{A}}=-\left(\frac{\partial l_{A}}{\partial w} \frac{w}{l_{A}}\right)$. Since the results are identical for all three policy cases, we can succinctly express the conditions together. Define $\delta$ as the relevant employment policy (here as payroll tax cuts, an increase in wage subsidy and a rise in aggregate demand). $\hat{\varepsilon_{\delta}}$ is the associated elasticity of the labor demand shift. The effects of the employment policies under union wage determination can be expressed as:

Proposition 1 If $\hat{w}-\hat{\varepsilon_{\delta}}>0$, the effectiveness of employment policies is magnified.

Alternatively, if $\hat{w}-\hat{\varepsilon_{\delta}}>0$, the effectiveness of employment policies is reduced.

Proposition 2 If $\left(\hat{w}-\hat{\varepsilon_{\delta}}+\hat{\gamma}\right)>0$, employment policies raise employment. Alternatively, if $\left(\hat{w}-\hat{\varepsilon_{\delta}}+\hat{\gamma}\right)>0$, employment policies lower employment.

As an alternative to Proposition 2, we could use (10) to state that if the shift of the labor demand is isoelastic, then employment policies raise (lower) employment if $1>R(1<R)$, where $R$ is the relative convexity of the labor demand curve. Proposition 1 and 2 show that in evaluating the impact of various relevant employment policies, taking the union's wage determination into account can alter the results significantly.

\section{Economic Integration and Employment Policies}

We next highlight how integration affects the effectiveness of the employment policies. The basic model is now extended to two firms and two unions, with one foreign firm and one foreign union. The unions move first to set their wage $w$ and $w^{*}$ to maximize their objectives:

$$
V=(w-b) l
$$




$$
V^{*}=\left(w^{*}-b^{*}\right) l^{*}
$$

Rent maximization yields

$$
\begin{gathered}
V_{w}=l+(w-b) l_{w}=0 \\
V_{w^{*}}^{*}=l^{*}+\left(w^{*}-b^{*}\right) l_{w^{*}}^{*}=0 \\
V_{w w}<0 \\
V_{w^{*} w^{*}}^{*}<0
\end{gathered}
$$

The international firms take $w$ and $w^{*}$ as given and set outputs $x$ and $x^{*}$,

$$
\begin{gathered}
\pi=x P\left(x, x^{*}, A\right)-w(1+\tau) l+s l \\
\pi^{*}=x^{*} P^{*}\left(x, x^{*}\right)-w^{*} l^{*} \\
\pi_{x}=0 \quad \pi_{x^{*}}^{*}=0 \\
\pi_{x x}=0 \quad \pi_{x^{*} x^{*}}^{*}<0
\end{gathered}
$$

From (11) to (14), we can write the domestic labor demand as $l(x(\tau, s, A)$, $w(\tau, s, A, b)$, and $\left.w^{*}(\tau, s, A, b)\right)$. As before, consider first the payroll tax cut. The total effect of a change of $\tau$ on $l$ is

$$
\frac{d l}{d \tau}=l_{\tau}+l_{w} \frac{d w}{d \tau}+l_{w^{*}} \frac{d w^{*}}{d \tau}
$$

The first termof (15) measures the direct effect of $\tau$ on domestic labor demand, holding $w$ and $w^{*}$ constant, the second term measures how the domestic union, by adjusting its wage demands, affects the domestic level of employment, and the third term measures how the foreign union's wage response affects the domestic level of employment. (15) is the open economy analogue of (7). The last term is only present with economic integration.

(15) can be rewritten as

$$
\frac{d l}{d \tau}=\hat{I}_{\tau}+\hat{U}_{\tau}+\hat{U}_{\tau}^{*}
$$

where $\hat{I}_{\tau}$ is the standard effect of a cut in payroll tax. In Section 4, we referred to this term as the "direct firm employment effect". Similarly, to keep the notation 
consistent with the closed economy version, we will refer to $\hat{U}_{\tau}$ as the "domestic union effect" and to $\hat{U}_{\tau}^{*}$ as the "foreign union effect" in the context of economic integration. At times, we will refer to the "aggregate union effect" as the sum of domestic union effect, $\hat{U}_{\tau}$, and the forign union effect, $U_{\tau}^{*}$.

The domestic and foreign wage responses are derived from (11) and (12), and are given as

$$
\begin{aligned}
& \frac{\partial w}{\partial \tau}=-\frac{V_{w \tau} V_{w^{*} w^{*}}^{*}}{\Delta} \\
& \frac{\partial w^{*}}{\partial \tau}=-\frac{V_{w \tau} V_{w^{*} w}^{*}}{\Delta}
\end{aligned}
$$

where $\Delta \equiv V_{w w} V_{w^{*}{ }^{*}{ }^{*}}^{*}-V_{w w}{ }^{*} V_{w}^{*}{ }^{*}{ }^{*}>0$ is the stability condition for the wagesetting unions. Let us now compare the effectiveness of a payroll tax cut in the open economy to the closed economy setting analyzed in Section 4.

For ease of comparison, we assume that the level of wages remains the same when we move from a closed economy setting to an open economy setting. ${ }^{12}$ The first term of (15) captures the conventional analysis of the employment effects of a change in $\tau$. Substituting (17) and (18) into the second and third terms of (15), we can express the aggregate union effect as:

$$
\operatorname{sn}\left[l_{w} w_{\tau}+l_{w}{ }^{*} w_{\tau}^{*}\right]=\operatorname{sn}\left[V_{w \tau}\right]\left[-\hat{e}+\hat{r}^{*} \hat{e}^{*}\right] \gtrless 0
$$

where $\hat{e} \equiv-\frac{\partial l}{\partial w} \frac{w}{l}$ is the elasticity of the domestic labor demand curve, $\hat{e}^{*} \equiv-\frac{\partial l}{\partial w^{*}} \frac{w^{*}}{l}$ is the elasticity of domestic employment with respect to the foreign union's wage, and $\hat{r}^{*} \equiv-\frac{d w}{d w} \frac{w}{w^{*}}$ is the elasticity of the foreign union's reaction function in the $\left(w^{*}-w\right)$ space (implicitly defined by $V_{w}^{*}$ in (12)). The term $s n$ is a sign effect. To highlight the factors driving the mechanisms under study, we are expressing a number of constant parameters implicit in expression (19) by a simple $s n$ expression: if the sign of the parameters left out from the right-hand side of the

\footnotetext{
${ }^{12}$ As Fung and Huizinga (1999) show, if we do not hold wages constant, domestic union wage can go up or down when the analysis switches from a closed economy to an open economy. In that case, we can denote $\Delta w$ as the additional effect on employment and the presentation will go through as in the text. The important point is that the qualitative results of the paper will remain: with economic integration, the effectiveness of the employment policies may be enhanced. But this is nit necessarily true and in some reasonable cases, it can even be reduced.
} 
expression is positive (negative), the left-hand side of the expression must also be multiplied by a positive (negative) sign. For clarity, we will be using this notation in the remaining of this section.

By (19), we note that the aggregate union effect can be either positive or negative. $\mathrm{V}_{w \tau}$ measures the impact of the payroll tax on the union's marginal rent. $\mathrm{V}_{w \tau}$ is negative (positive) if the domestic union can extract higher rents by increasing (decreasing) its wage demands in response to a cut in payroll taxes. Focusing on the case of $V_{w \tau}<0$, we have a third result for the paper: if $\left(-\hat{e}+\hat{r}^{*} \hat{e}^{*}\right)>0$, the effectiveness of a payroll tax cut is magnified with economic integration. But if $\left(-\hat{e}+\hat{r}^{*} \hat{e}^{*}\right)<0$, the effectiveness of a payroll tax cut is dampened. If $V_{w \tau}>0$, the results are reversed.

Intuitively, when $V_{w \tau}<0$, the domestic union extracts higher rents when raising its wage demands following a reduction in the payroll taxes. In addition, when $\left(-\hat{e}+\hat{r}^{*} \hat{e}^{*}\right)>0$, the positive employment effects due to the foreign union's desire to raise its own wage demands exceeds the negative employment effect due to the domestic union's desire to raise its wage demands in response to lower payroll taxes. Under these circumstances, the presence of a foreign union, which responds to higher domestic wages by raising its own wage demands, can mitigate the negative domestic union effect on domestic employment and hence, raise the effectiveness of a cut in payroll taxes.

Alternatively, we can simplify all three terms of (15) to yield the open economy analogue of (9),

$$
\operatorname{sn}\left(\frac{d l}{d \tau}\right)=\operatorname{sn}\left[l_{w}\left(\hat{w}-\hat{\varepsilon}_{\tau}+\hat{\gamma}\right)-l_{w} \hat{w}^{*}\left(\hat{\varepsilon}_{\tau}-\hat{\gamma}^{*}\right)\right]
$$

where $\hat{w}, \hat{\varepsilon}_{\tau}$ and $\hat{\gamma}$ are as defined in Section $5 . \hat{\gamma}^{*} \equiv-\frac{\partial l_{w}}{\partial w} \frac{w}{l_{w}{ }^{*}}$ is the elasticity of $l_{w}$. with respect to the domestic wage. Note that the expression $\left(\hat{w}-\hat{\varepsilon}_{\tau}+\hat{\gamma}\right)$ is the same condition required to sign the domestic union effect stated in Proposition 2. Also using (12)-(14), $l_{w^{*}}>0$. We can use (20) to obtain the counterintuitive result for the open economy case: if in addition to $\left(\hat{w}-\hat{\varepsilon}_{\tau}+\hat{\gamma}\right)<0,\left(\hat{r}^{*}\left(\hat{\varepsilon}_{\tau}-\hat{\gamma}^{*}\right)\right)<0$, a reduction in payroll taxes may generate lower employment

in the context of economic integration. Assume that the foreign labor union responds

to a higher domestic wages by lowering its own wage demands $\left(\hat{r}^{*}>0\right)$.

In this case, a payroll tax cut will reduce the domestic level of employment if the 
negative domestic employment response due to lower foreign wages $\left(\hat{\gamma}{ }^{*}\right)$ exceeds the firms' positive employment response to lower payroll taxes $\left(\varepsilon_{\tau}\right)$.

As before, if we assume that shifts of labor demand are isoelastic, we can rewrite (20) as

$$
\operatorname{sn}\left(\frac{d l}{d \tau}\right)=-\operatorname{sn}\left(1-\bar{R}-\hat{r}^{*} \hat{R}^{*}\right)
$$

where $\bar{R}$ and $\hat{r}^{*}$ are defined as before. $\hat{R}^{*} \equiv-(w-b) \frac{l_{w w^{*}}}{l_{w}}$ is the proportional change of the slope of the home labor demand as the foreign wage changes. According to this expression, in response to a cut in payroll taxes, employment drops if and only if $\left(1-\bar{R}-\hat{r}^{*} \hat{R}^{*}\right)<0$. (21) is the open economy analogue of (10). Again, assuming that the foreign labor union responds to a higher domestic wages by raising its own wage demands $\left(\hat{r}^{*}>0\right)$, ceteris paribus, the level of domestic employment will fall in response to a cut in domestic payroll taxes if the domestic labor demand curve is highly sensitive to an increase in foreign wages.

As before, we can state (21) to state an alternative to Proposition (4): with isoelastic shift in labor demand, domestic employment policies raise domestic employment $i .1>\left(\hat{R}+\hat{r}^{*} \hat{R}^{*}\right)$. Domestic employment policies lower domestic employment $i$. $1>\left(\hat{R}+\hat{r}^{*} \hat{R}^{*}\right)$.

More generally, our results can be extended to other employment policies designed to affect the cost structure of the domestic firm. For example, domestic employment policies such as wage subsidies and aggregate demand expenditure yield identical results to those derived above. For the sake of brevity, we will skip the details, since the derivations follow from the analysis presented above.

We will only present the generalized results. Again, let $\delta$ be any of the three employment policies. Assume $V_{w \delta}<0$ and denote $\left(\hat{w}-\widehat{\varepsilon}_{\delta}-\hat{y}\right)$ as condition $\hat{C}$ and $\left(\hat{w}-\hat{\varepsilon}_{\delta}+\hat{y}\right)<0$ as condition $\hat{C}^{*}$. We can summarize then our results under economic integration as

Proposition 3 If $\left(-\hat{e}+\hat{r}^{*} \hat{e}^{*}\right)>0$, the effectiveness of employment policies is magnified. If $\left(-\hat{e}+\hat{r}^{*} \hat{e}_{*}\right)<0$, the effectiveness of employment policies is magnified.

Proposition 4 If $\hat{r}^{*}\left(\hat{\varepsilon}_{\delta}-\hat{r}^{*}\right)>0$ and $\hat{C}$ holds, domestic employment policies raise domestic employment. If $\hat{r}^{*}\left(\hat{\varepsilon}_{\delta}-\hat{r}^{*}\right)<0$ and $\hat{C}^{*}$ holds, domestic employment policies raise domestic employment.

Let us now consider a policy that does not affect domestic wages directly. We next consider cuts in unemployment benefits, $b$, which unlike other policies studied 
here, do not affect the domestic union directly. With economic integration, the total impact on employment is

$$
\frac{d l}{d b}=l_{b}+l_{w^{*}}\left(\frac{\partial w^{*}}{\partial b}\right)
$$

The first term measures the effect in closed economy (see (5)). The second term measures the wage response from the foreign union. Using (12),

$$
\operatorname{sn}\left[l_{w^{*}}\left(\frac{\partial w^{*}}{\partial b}\right)\right]=\operatorname{sn}\left(\hat{e} \hat{e}^{*} \hat{r}^{*}\right)
$$

$\hat{e}, \hat{e}^{*}$ and $\hat{r}^{*}$ are defined earlier in (19). Since $\hat{e}$ and $\hat{e}^{*}$ are both positive, whether economic integration will enhance or dampen the impact of cuts in unemployment benefits depends on the sign of $\hat{r}^{*}$, the sensitivity with which the foreign union adjusts its wage demands in response to a change in domestic wages.

Alternatively, expression (22) can be re-written as follows:

$$
\operatorname{sn}\left(\frac{d l}{d b}\right)=\operatorname{sn}\left(-\hat{e}+\hat{e}^{*} \hat{r}^{*}\right)
$$

We summarize the results associated with cuts in unemployment benefits in the open economy as:

Proposition 5 If $\hat{r}^{*}<0$, a cut in domestic unemployment benefits is more effective with economy integration. If $\hat{r}^{*}>0$, a cut in domestic unemployment benefits is less effective with economic integration.

Proposition 6 If $\left(-\hat{e}+\hat{e}^{*} \hat{r}^{*}\right)<0$, a cut in domestic unemployment benefits raises domestic employment. If $\left(-\hat{e}+\hat{e}^{*} \hat{r}^{*}\right)>0$, a cut in domestic unemployment benefits lowers domestic employment.

Overall, we have demonstrated that both the domestic union's wage response and the foreign union's wage response may affect the effectiveness of domestic employment-enhancing policies. Given the general closed economy argument presented in Section 4, our analysis and results could be easily extended to the open economy case with economic integration. One straightforward generalization could be to analyze the case with $m$ domestic firms and $(n-m)$ foreign firms. Using the logic of Section 4, it can be readily seen that there will be cases where employment-enhancing policies will yield paradoxical outcomes. 


\section{Conclusion}

The paper highlight how economic integration and endogenous wage determination can significantly affect the overall impact as well as the degree of effectiveness of several important employment-promoting policies, including payroll tax cuts, wage subsidies, an expansionary demand policy and cuts in unemployment benefits. When analyzed in the context of an isolated firm or an isolated union, it is straightforward to see that these policies will lead to an increase in employment. However, in a more realistic setting, we need to take the endogenous wage reactions from the domestic union into account. Furthermore in an increasingly integrated world economy, we need to further analyze the wage response from abroad.

Intuitively, proposed changes to labor market policies (e.g., payroll tax cuts) will generally have three effects. First, holding the domestic wage rate constant, the derived labor demand will shift out. This shift is generally employment enhancing. But such a shift need not be isoelastic. The economy can end up at a point of the labor demand curve that is more or less convex. Second, with a domestic labor union, the union can raise the wage rate in the face of a higher demand for labor. This will be employment-reducing. Lastly, with a foreign firm losing sales to the domestic firm, the foreign union can lower its wage to increase foreign employment. This will shift the domestic labor demand curve in. The net outcome is ambiguous and it explains why changes to labor market policies can paradoxically reduce employment.

Overall, this paper highlights some interesting properties of employment policies in a framework of endogenous wages, both in a closed economy as well as in an open economy. Our model is particularly relevant for the current high unemployment situation in Europe.

\section{Acknowledgments}

This paper is supported by a grant from the Center for German and European Studies, University of California, Berkeley and an Academic Senate Research Grant, University of California, Santa Cruz. A previous version of this paper was issued as Working Paper 2.69 of the Center for German and European Studies, University of California, Berkeley. Gaofeng Han and I-Chu Chung provided capable research assistance. All errors are ours. 


\section{References}

Abowd, J. and T. Lemieux, (1990), "The effects of international competition on collective bargaining outcomes: a comparison of the United States and Canada," NBER Working Paper Series, No. 3352.

Alogoskoufis, G., (1990), “The labor market in the open economy," in Sapsford, D. and Z. Tzannatos (ed.), Current Issues in Labour Economics, Macmillan Education Ltd., London.

Bean, C, R. Layard and S. Nickell (ed.), 1986, Unemployment Supplement, Economics, 53.

Blanchard, O., R. Dorbusch, J. Drèze, H. Giersch, R. Layard and M. Monti, (1986), "Employment and growth in Europe: a two-handed approach," in Blanchard, $O$. et al., Restoring Europe's Prosperity, MIT Press, Cambridge.

Blanchard, O. and L. Summer, (1986), "Hysteresis and the European unemployment problem," in Fischer S. (ed.), NBER Macroeconomic Annual, MIT Press, Cambridge.

Blanchard, O. and J. Wolfers, (2000), "Shocks and Institutions and the Rise of European Unemployment. The Aggregate Evidence," Economic Journal, 110(1):1-33.

Bruno, M. and J. Sachs, (1985), The Economy of Worldwide Stagflation, Basil Blackwell, Oxford.

Coen, R. and B. Hickman, (1987), Keynesian and classical unemployment in four countries, Brookings Papers on Economic Activity, 1, 123-205.

Farber, H, (1986), The analysis of union behavior, in O. Ashenfelter and R. Layard (ed.), Handbook of Labor Economics, v. 2. North Holland, Amsterdam.

Fung, K.C., (1989), "Profit-Sharing and European Unemployment", European Economic Review, 33:1787-1798.

Fung, K.C. and H. Huizinga, (1999), "Economic Integration and Firm-Union Interaction: The Role of Market Structure", Journal of Economic Integration, 14(4):554-571, December.

Giersch, H., (1985), Eurosclerosis, Kiel Institute for World Economics Discussion Paper, Number 112.

Lawrence, R. and C. Schultze (ed.), (1987), Barriers to European Growth: A Transatlantic View, Brookings Institute, Washington, D.C.

Layard, R. and L. Calmfors (ed.), (1987), The Fight Against Unemployment, MIT Press, Cambridge.

Lindbeck, A., (1985), "What is wrong with the West European economies?" World Economy, 8:153-170.

Lindbeck, A. and D. Snower, (1986), "Wage setting, unemployment and insider-outsider relations," American Economic Review, Papers and Proceedings, 76, 235-239.

Lindbeck, A., (1989), "Demand and supply side policies and unemployment policy implications of the insider-outsider approach".

Machin, S. and Manning, A., (1998), "The Causes and Consequences of Longterm 
Unemployment in Europe, “ in Ashenfelter, O. and Card, D., eds, Handbook of Labor Economics, Volume 3C, (North-Holland, Amsterdam), 3085-3139.

McDonald, I. and R. Solow, (1981), "Wage bargaining and employment," American Economic Review, 71:896-908.

Minford, P., (1983), "Labour market equilibrium in an open economy," Oxford Economic Papers, 35:207-244.

Nickell, S., (1997), "Unemployment and Labor Market Rigidities: Europe versus North America," Journal of Economic Perspectives, 11(3):55-74.

Nickell, S. and Layard, R., (1998), "Labor Market Institutions and Economic Performance," in Ashenfelter, O. and Card, D., eds, Handbook of Labor Economics, Volume 3C, (North-Holland, Amsterdam), 3029-2084.

OECD, (2002), OECD Economic Outlook No. 72, Paris: France.

Oswald, A., (1982), "The microeconomic theory of the trade union," Economic Journal, 92:576-595.

Oswald, A., (1984), "Effcient contracts are on the labor demand curve: theory and facts," Princeton University Industrial Relations Sections Working Paper 178.

Siebert, H. (1997), "Labor Market Rigidities: At the Root of Unemployment in Europe," Journal of Economic perspectives, 11(3):37-54.

The Economist, 1997, "How not to Make Jobs in Europe," November 27, 1997. 